\title{
Converting cumulative grade point average to an equivalent percentage value based on a fuzzy logic
}

\author{
Ibrahim Eldesouky Fattoh ${ }^{1}$, Farid Ali Mousa ${ }^{2}$, Soha Safwat ${ }^{3}$ \\ ${ }^{1}$ Computer Science Department, Beni-Suef University, Beni Suef, Egypt \\ ${ }^{2}$ Information Technology Department, Beni-Suef University, Beni Suef, Egypt \\ ${ }^{3}$ Software Engineering and Information Technology Depertment, The Egyptian Chinese University, Cairo, Egypt
}

\begin{tabular}{l} 
Article Info \\
\hline Article history: \\
Received Jun 4, 2021 \\
Revised Oct 14, 2021 \\
Accepted Oct 27, 2021 \\
\hline
\end{tabular}

\section{Keywords:}

Cumulative grade point average

Fuzzy logic

Grade point average

Membership function

Percentage

\begin{abstract}
The graduates who have finished their study program will be given a merit award and their award certificates will be graded in accordance with the degree of their academic accomplishment. The awards are generally offered using two methods; one is by the cumulative grade point average (CGPA) and the other is by the average percentage of all marks for the students. The problem is when assigning a course final grade; each student's final percentage is translated to a letter, allowing the discrepancy within the same letter grade range in the final ranking. If two students have the same final score, that means equal results. However, this equality can be false if one student hits a percentage of the highest grade, while the second student earns a percentage of the lowest grade of the same letter grade. This paper introduced a new equation that transforms between the awarded cumulative grade point average and the awarded percentage ranking based on fuzzy system. The proposed approach was tested using three actual benchmarks collected from three different colleges in Beni-Suef university. The obtained results reflects the effect of the fuzzy logic in helping converting form CGPA measures to percentage measure in educational systems.
\end{abstract}

This is an open access article under the CC BY-SA license.

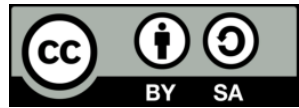

\section{Corresponding Author:}

Farid Ali Mousa

Information Technology Department

Beni-Suef University

Beni Suef, Beni Suef Governorate, Egypt

Email: fared.ali@fcis.bsu.edu.eg

\section{INTRODUCTION}

The performance of students in an academic program is measured by their final grades in the requisite courses. These grades come from the distribution of letters or numbers given by the course instructor to summarize all the assessments of the student's evaluation results. The scale used to assign grades is therefore particularly significant, among other factors. Student grade point average (GPA) is a statistic that reflects how well or how high you have achieved in your courses [1]. It helps to assess you during your studies usually with a GPA scale between 1.0 and 4.0 and demonstrates whether your total class ranks are high or low. This number is then used to determine whether you meet the expectations and criteria set by the faculty degree [2]. Your GPA is basically the only indicator of how successful you are, and whether you have done well in the history of your graduation, in your university education. If you are clearly conscious of your passage and excellence in your classes, your GPA offers a wider indicator of your overall skills and ratings [3].

For example; many educational systems in some countries, grades are typically given in two ways. First, by using the average grade percentage of courses. Adding the marks of all courses and then dividing 
this value by the number of courses and multiplying by 100 , this value reflects the percentage of student marks in the program; then it is translated into an award degree such as (excellent, very good, good, pass or fail). The second method is to use the GPA [4]. Each student's final percentage is translated into a letter that masks all differences in the final score obtained within that letter. If two students have the same final score, that means equal results. This equitable output portrayal can still be inaccurate if one student attained a degree at the top of the letter grade range, whereas a second student obtained a percentage grade below the same letter grade level (e.g., 89\% and 81\%). Decreasing the range of letter scores with plus or minus grading means less exaggeration of the results of students and more fine variations. The assumption is, however, that the gap in results between 2 or 3 percentage points is important. The faculty evaluations will reliably distinguish between these performances ranges. In this research; we introduce a new equation based on fuzzy system that helps in transforming between the awarded cumulative grade point average and the awarded percentage ranking to help educational systems in accepting transferring students and ranking the students between different universities that use different evaluation methods.

Education degrees are the method of applying uniform metrics of various standards of efficiency. Grades can be distributed as letters (e.g., A to F), as a series (e.g., 1 to 6, as a percentage of the total number of correct answers to the questions or as a number from a possible total (e.g., out of 20 or 100). The overall proportion of all classes in certain countries or a grade point average (GPA) is averaged by all grades of all current classes. The GPA is determined by the grade points gained by a student in a given period of time. For bachelor and graduate students in most universities, GPAs also are determined. The GPA may be used for assessing and comparing candidates for prospective employers or educational institutions [5]. Calculating the total earned points of a student divided by the possible number of points, is known as a cumulative grade point average (CGPA). The average of this ranking scheme for all of the student's education career is determined [6].

Grade point averages could be unweighted; where all groups with the same credits have the same effect on the GPA, or could be weighted; where some classes than others are given more influence. A degree scheme is established by means of the acceptance process for undergraduate or graduate courses. For most academic, technical and job focused courses, letter rating schemes (grades applicable to GPA) are mostly used. Letter grades can also be used in the case of non-credit courses, where GPA ratings are not available. The meaning of the final letter grade is based on regular percentage equivalents. The final percentage is rounded to the nearest integer by normal statistical procedure before translating it to a letter grade (i.e., rounding to the next higher integer if the first digit after the decimal place is 5 or higher) [7].

The student's credits are based on the academic load credits of the passed modules. The calculation of cumulative credit hours of the repeated modules will be counted once. In order to measure total GPA, the highest achieved GP is used. The accumulated GPA estimate for each student begins from the first semester and is updated till the student graduation in each semester. The student's semester GPA is the weighted average of the grade points obtained in the modules taken during that particular semester as calculated in (1) and (2) [8].

$$
\begin{aligned}
& \text { Semester GPA }=\frac{\sum \text { Points for course } \times \text { Credit hour fo the coure }}{\sum \text { total registered credit hours for the semester }} \\
& \text { Cumulative GPA }=\frac{\sum \text { Points } \text { for all course } \times \text { Credit hour fo the coure }}{\sum \text { total registered credit hours for all semester }}
\end{aligned}
$$

\section{PROPOSED SYSTEM}

The goal of this paper is to translate the awarded cumulative GPA into an equivalent percentage, which will help students transfer in two educational systems. The proposed model is helpful in many situations; one of them is transferring students from one university to another that have different assessment; also can help in case of ranking students from different universities.

Since the number of people who graduated from a university has increased. There is a high competition among the graduates in white collar job market. One of the indicators that highlight the university students' qualification is the academic performance, there are different evaluations in universities, the proposed model used to find a way to compare all students in one way. methodology:

Algorithm 1, describes the basic steps of the proposed model equations based on the fuzzy logic

Algorithm 1: proposed fuzzy model to convert CGPA to equivalent percentage value:

a) Input:

- $\quad$ Matrix M with letter grades and corresponding GPA with the awarded degree for a given faculty.

- Cumulative GPA CUM $M_{G P A}$. 
b) Calculate the minimum points $M i{ }_{-} \_o_{i}$ and maximum points $M a x_{-} p o_{i}$ for the given matrix M:

$$
\begin{aligned}
& \operatorname{Min}_{p_{o}}=\operatorname{Minimum}(\text { Grade Letter Points }) \\
& \operatorname{Max}_{p o}=\operatorname{Maxmimum}(\text { Grade Letter Points })
\end{aligned}
$$

c) Calculate the minimum percentage $M_{i n} \_p e r_{i}$ and maximum percentage $M a x_{-} p e r_{i}$ for the given matrix M:

$$
\begin{aligned}
& \text { Min }_{\text {per }}=\text { Minimum }(\text { Grade Letter Percentage }) \\
& \text { Max }_{\text {per }}=\text { Maxmimum }(\text { Grade Letter Percentage })
\end{aligned}
$$

d) Calculate the membership value for the $C U M_{-} G P A$ :

$$
\mu=\frac{C U M_{-} G P A-M i n_{-} p o_{i}}{\operatorname{Round}\left[M a x_{\_} p o_{i}\right]-M i n_{-} p o_{i}}
$$

e) Output for this cumulative GPA is:

$$
\text { Output Percentage }=[\boldsymbol{\mu} \times \boldsymbol{d}]+\text { Min_per }_{i}
$$

Such that:

f) $\quad d=$ Round $\left[\right.$ Max_per $\left._{i}\right]-$ Min_per $_{i}$

The inputs to the proposed method are the matrix $M$ with grade letters and corresponding GPA and the cumulative GPA that should be converted to percentage. The system will start by calculating Minimum point using (3) that will take the minimum point to the corresponding cumulative GPA from the matrix M. With the same we will used (4) to get the maximum point to the input cumulative GPA. The minimum and maximum percentage to each grade letter in matrix $M$ will calculated using (5) and (6). The next step is calculating the membership value to the entered cumulative GPA using (7). The novel membership function in the proposed algorithm guarantee of picking a value 1 to highest cumulative GPA and a value 0 to minimum cumulative GPA. After calculating the membership function $\mu$, it will be multiplied by the percentage difference of the appropriate range where the cumulative GPA fall in between, followed by adding this value to the minimum percentage as shown in (8) and (9).

\section{PROPOSED SYSTEM}

The novel equations used in this paper is based on fuzzy logic, the mathematical basis of the fuzzy logic lies in the fuzzy set theory of a classical set theory, which can be viewed as a generalization. Fuzzy logic is a strong problem-solving technique for a variety of embedded control and information technology applications. Fuzzy provides a surprisingly clear way in which final judgments are derived from vague, unclear or incorrect information. In some sense, fuzzy logic resembles the ability of the human being to function with approximate data and find specific solutions. Over the last few years, fuzzy logic has been widely accepted as a method for solving problems. More than two thousand commercial products, ranging from washing machines to high-speed trains, are usable via fuzzy logic. Fuzzy logic benefits can be realized in its performance, simplicity, lower cost and efficiency in every application [9].

Fuzzy is a computing technique focused on "degrees of truth" and not on "true or false" techniques ( 1 or 0 ) as the typically basis of the digital computer. Lotfi Zadeh from the University of California in Berkeley, was the first to invent the notion of fuzzy logic in the sixties. The dilemma that prompted Zadeh to learn about the fuzzy logic was to overcome the problem of computer knowledge of natural language [10].

Translating the natural language into 0 and 1 is very complicated. Two extreme cases of the fact (truth), which are zero and one are part of fuzzy logic. It also covers the various cases of fact (truth) in between, e.g., the outcomes of a comparison of two items can't be 'tall' or 'short' only, but a value of ' 0.38 tallness'. An easier way to simplify this concept is allowing more values from 1 to 0 . In particular, some alternatives have the potential to be allowed between the limits 0 to 1 , i.e., the interval of the unit $\mathrm{I}=[0,1]$.

It is much harder to translate the numbers allocated to each element. This implies that the number 1 will be assigned to an element, if the element is in set ' $A$ '. If the element is not in ' $A$ ' set, that implies that an element will be given the number 0 . All other values mean that the set 'A' is steadily incorporated [10]. 


\subsection{Characteristics of fuzzy logic}

In 1992, Zadeh laid down a set of fundamental rules of fuzzy logic [11]:

- Correct reasoning shall be treated as an estimated reasoning scenario.

- Everything is considered a matter of degree.

- Knowledge is understood as an elastic, fuzzy constraint on a group of variables.

- Inference shall be treated as an elastic constraint propagation mechanism.

- Any logical system shall be "fuzzy". applications:

There are two main features of fuzzy systems, provide improved performance for particular

- Fuzzy systems are suitable, in particular for the system with a mathematical model that is difficult to extract and ideal for unclear or approximate purposes.

- Fuzzy logic helps decisions with approximate values in incomplete or ambiguous information.

\subsection{Membership creation}

The fuzzy relation concept of a classical relationship is generalized by introducing a partial membership between $\mathrm{x}$ and y elements. Examples of fuzzy relationships are "similar, approximately equal and much larger". The cartesian product of $\mathrm{X}$ and $\mathrm{Y}$ defines the fuzzy relation between set ' $\mathrm{X}$ ' and set ' $\mathrm{Y}$ ' is established. Taking a subset of a certain cartesian product ' $X Y$ '. A fuzzy set 'A' membership function on the discourse universe $X$ is well-defined as: $\mu_{\mathrm{A}}: X \rightarrow[0,1]$, where the value of each $X$ element is mapped from 0 to 1 . This value is called a membership value or membership degree, quantifies the membership grade of the elements in $\mathrm{X}$ to the fuzzy set 'A'. Membership functions allows graphical representation of a fuzzy set, where the $\mathrm{X}$-axis represents the discourse universe, while the $\mathrm{y}$-axis represents the membership degrees inside the interval $[0,1][11]$.

To construct membership functions, simple functions are used. Using complex functions in fuzzy concepts don't offer more accuracy. The simplest membership functions are generated by straight lines. The easiest of these is the triangular function membership (3), and its name is trimf. It's just a three-point set making a triangle. The membership function of the trapezoidal (4), trapmf, has a flat top and is really just a truncated triangle curve. The benefit of these straight line membership functions is simplicity. Here are some membership functions used in the literature for solving many applications [12].

- Triangular function is defined as a lower limit ' $a$ ', a value of ' $m$ ' and an upper limit ' $b$ ', where $a<m<b$ :

$$
\mu_{A}(x)=\left\{\begin{array}{lr}
0, & x \leq a \\
\frac{x-a}{m-a}, & a<x \leq m \\
\frac{b-x}{b-m} & m<x<b \\
0, & x>b
\end{array}\right\}
$$

- Trapezoidal function is defined as a lower limit 'a', a lower support limit 'b', an upper limit 'd' and an upper support limit 'c', where $\mathrm{a}<\mathrm{b}<\mathrm{c}<\mathrm{d}$.

$$
\boldsymbol{\mu}_{\boldsymbol{A}}(\boldsymbol{x})\left\{\begin{array}{lr}
0, & (x<a) \text { or }(x>d) \\
\frac{x-a}{b-a}, & a<x \leq b \\
1 & b<x< \\
\frac{d-x}{d-c}, & c \leq x \leq d
\end{array}\right\}
$$

- Gaussian function is known as ' $\mathrm{m}$ ', central value and ' $\mathrm{k}$ ', a standard deviation $>0$. The smaller the $\mathrm{k}$, the narrower the bell.

$$
\mu_{A}(x)=e^{-\frac{(x-m)^{2}}{2 k^{2}}}
$$

\subsection{Fuzzy logic in educational system}

In this section, some of the fuzzy most recent research areas are introduced for addressing particular problems in diverse fields of study. One of the very early approaches in e-learning modeling was the fuzzy logic. In [13], the reflection of an assessment method, learning environment was proposed. Fuzzy logic helps to lay all the knowledge in a computational way and make it highly imprecise [14]. It implemented a method called taps for grading students, which uses fuzzy logic to assign grades of membership to language labels. Systems like Sherlock II [15] and medium-density fiberboard (MDF) tutor [16] have used fuzzy distributions and a variety of rules to represent, identify, and update student behavioral instability. The brilliant scholar 
series 1 (BSS1) tutoring framework in [17] and sypros in [18] have been developed to be introduced with a fuzzy logic engine. It provides an optimized student learning management based on these strategies. Degree [19] is a method that enables knowledge to be retrieved at a number of stages. Their authors assess and model the variables with linguistic variables in qualitative terms. The learning partnership method is defined from this point of view. The fuzzy inference method explains the group behavior in compliance with group rules and variables. The previous work overlooked the particular facets of the domain. In this respect, the DomoSim-TPC system [20] automatically uses methods to allow education professionals to evaluate the outcomes of classroom activities. Fuzzy inference can be used in collective learning to draw decisions about students and their actions.

In [21], fuzzy rules of association were used to explain the connections among the different pattern's behavior of a learner. The parameters under examination include the number of questions answered, the online time spent and the number of articles read and written. This technique is done by the fuzzy approach to change typical site logs. To reflect the evaluations of the teacher, fuzzy inferences are suggested in [22]. It contributes by processing and aggregating membership rules to infer learners' awareness and cognitive skills. Additional grading tasks are in [20]. It researched the perspectives of specialists to create a new way of measuring the academic success of students. In order to accomplish this task, the fuzzy rules were applied, which included a fuzzy inference system and an associated rule algorithm for the induction. In this context, concept maps represent another big advantage. In [23], a new technique is proposed to construct them automatically. It was then extended to multiple adaptive education systems. This work uses reasoning techniques and fuzzy rules. It produces concept maps and assesses the importance of connections between concepts. Sue et al. [24] built the concept map automatically using the historical testers of educators, by means of a two-phase concept map construction (TP-CMC). Fuzzy logic takes priority in the first step, where the numerical values of the test records are converted into symbolic data. In this step, the approach to data mining is used to define the rules of the fuzzy association. The writers used several rules in realistic learning scenarios according to their findings, in the second phase. A full learning architecture is proposed in [25] beyond individual techniques. It promotes individual education focused on a method of education built for intelligent agents. The rules set in this case is based on a fuzzy inference engine. It allows mathematical language rules to be described and code to be created automatically.

In [26] the technique for fuzzy inductive reasoning forecasts the eventual outcomes of students on a simulated campus. Real assessment evaluations were performed, low bugs were rendered and the teacher's tasks were decreased in difficulty. The study in [27] suggests another method of fuzzy inference mechanism for recommending the option of content for any student by educators. They encourage educators to be directed with their students along with the desires of learners, analytical hierarchy processes and memories loop updates. While in [28], a modern recommendation system of fuzzy matching rules is provided in the adaptive and intelligent web-based education system to find the required learning content that best suits the needs of each student. This recommended system could assist students and aid teaching online.

Also, the fuzzy logic was used as method for evaluating students performance and as a grading model for students as in [29], [30]. From the literature, we observed that the fuzzy logic is used in many educational systems for different purposes, while this research is considered the first one, which uses the fuzzy logic to convert from one grading system to another one. This will help educators and educational organizations in accepting transferred students form educational organization to another one, also help in ranking the students according to their grades.

\section{RESULTS AND DISCUSSION}

To evaluate the proposed model, we have collected three different datasets from three different faculties in the University of Beni-Suef. The three datasets differ in the number of available GPA points in each one and the awarded degree and the range of percentage values according to the GPA points.

\subsection{Faculty of computers and artificial intelligence}

The first dataset is collected from faculty of computers and artificial intelligence. The different grading points range from 0 to 4 . The awarded degree from excellent to fail. Table 1, shows GPA in points, the awarded degree and the corresponding percentage range for each GPA points range.

Table 1. Dataset 1-faculty of computers and artificial intelligence

\begin{tabular}{cccclll}
\hline Max Per & Min Per & Max-Points & Min Points & \multicolumn{1}{c}{ Percentage } & Awarded Degree & Points \\
\hline 100 & 90 & 4 & 3.7 & Percentage $>=90$ & Excellent & GPA $=4$ \\
100 & 85 & 4 & 3.7 & $90>$ Percentage $>=85$ & Excellent & $4>$ GPA $>=3.7$ \\
$<85$ & 80 & $<3.7$ & 3.3 & $85>$ Percentage $>=80$ & Very Good & $3.7>$ GPA $>=3.3$ \\
$<80$ & 75 & $<3.3$ & 3 & $80>$ Percentage $>=75$ & Very Good & $3.3>$ GPA $>=3$ \\
$<75$ & 70 & $<3$ & 2.7 & $75>$ Percentage $>=70$ & Good & $3.0>$ GPA $>=2.7$ \\
$<70$ & 65 & $<2.7$ & 2.3 & $70>$ Percentage $>=65$ & Good & $2.7>$ GPA $>=2.3$ \\
$<65$ & 60 & $<2.3$ & 2 & $65>$ Percentage $>=60$ & Pass & $2.3>$ GPA $>=2.0$ \\
$<60$ & 0 & $<2$ & 0 & $60>$ Percentage $>=0$ & Fail & $2.0>$ GPA $>=0$ \\
\hline
\end{tabular}

Converting cumulative grade point average to an equivalent percentage... (Ibrahim Eldesouky Fattoh) 
Also the minimum points (Min_Points), maximum points (Max_Points), minimum percentage (Min_Per) and maximum percentage (Max_Per) that were calculated to cumulative GPA for data set 1 that will be used in (7)-(9) are shown in Table 1. Table 2 and Figure 1 show, the output of the novel equations by calculating the percentage of a given cumulative GPA of some students in the given dataset shown in Table 1 .

Table 2. Percentage calculations for a given cumulative GPA for data set 1

\begin{tabular}{cccl}
\hline Cumulative GPA & Member & Percentage & Awarded Degree \\
\hline 3.9 & 0.667 & 95.00 & Excellent \\
3.75 & 0.167 & 87.5 & Excellent \\
3.71 & 0.03 & 85.5 & Excellent \\
3.68 & 0.95 & 84.75 & Very Good \\
3.35 & 0.125 & 80.625 & Very Good \\
3.1 & 0.33 & 76.67 & Very Good \\
2.75 & 0.16 & 70.8 & Good \\
2 & 0 & 60 & Pass \\
1.8 & 0.33 & 56.67 & Fail \\
1.4 & 0.25 & 51.25 & Fail \\
0.9 & 0.9 & 40.5 & Fail \\
\hline
\end{tabular}

\subsection{Faculty of science}

The second dataset is collected from faculty of science. The range of GPA points are less than the range in dataset 1 . Table 3 , shows three columns that represents the GPA in points, the awarded degree and the percentage. Also, Table 3, shows the calculated the minimum points (Min Points), maximum points (Max_Points), minimum percentage (Min_Per) and maximum percentage (Max_Per) to cumulative GPA for dataset 2. These values that will be used in equation 7 to compute the membership function, then equations 8 and 9 to calculate the proposed percentage value. Table 4 and Figure 2, show the novel equations are tested by calculating the percentage of a given cumulative GPA of some students in the given dataset shown in Table 4

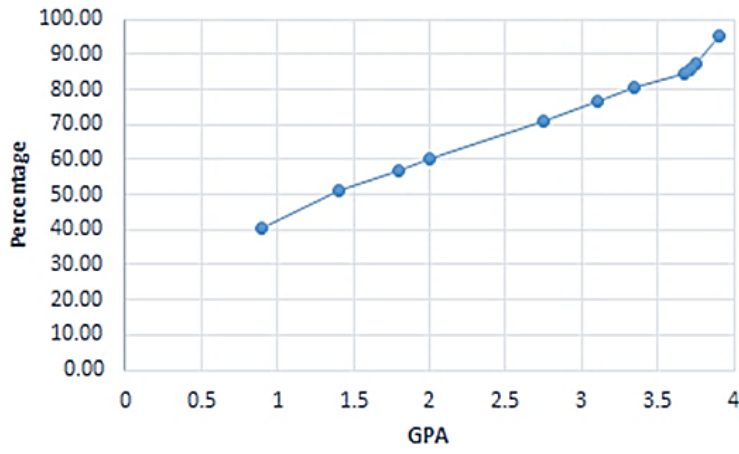

Figure 1. Relation between cumulative GPA and percentage for dataset 1

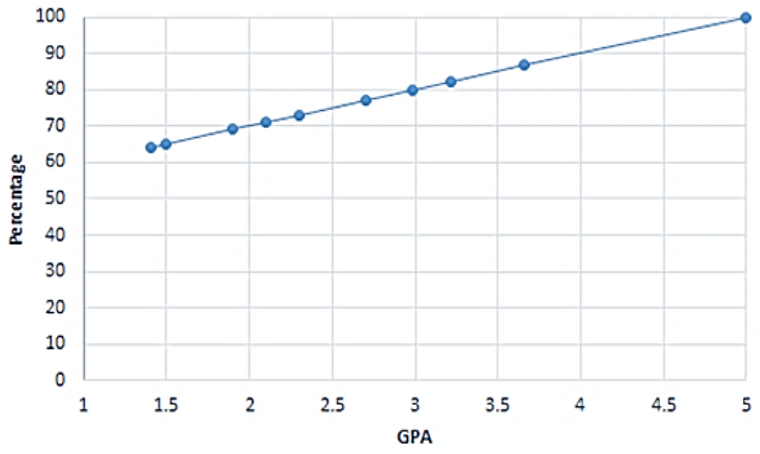

Figure 2. Relation between cumulative GPA and percentage for dataset 2

Table 3. Dataset 2-faculty of science

\begin{tabular}{lllcccc}
\hline \multicolumn{1}{c}{ Points } & Awarded degree & \multicolumn{1}{c}{ Percentage } & Min Points & Max Points & Min Per & Max per \\
\hline GPA $>=3.5$ & Excellent & Percentage $>=85$ & 3.5 & 5 & 85 & 100 \\
$3.5>$ GPA $>=2.5$ & Very Good & $85>$ Percentage $>=75$ & 2.5 & $<3.5$ & 75 & $<85$ \\
$2.5>$ GPA $>=1.5$ & Good & $75>$ Percentage $>=65$ & 1.5 & $<2.5$ & 65 & $<75$ \\
$1.5>$ GPA $>=1$ & Pass & $65>$ Percentage $>=60$ & 1 & $<1.5$ & 60 & $<65$ \\
$1>$ GPA & Fail & $60>$ Percentage & 0 & $<1$ & 0 & $<60$ \\
\hline
\end{tabular}

Table 4. Percentage calculations for a given cumulative GPA for dataset 2

\begin{tabular}{ccclllll}
\hline Cumulative GPA & Member & Percentage & Awarded Degree & Cumulative GPA & Member & Percentage & Awarded Degree \\
\hline 5 & 1.00 & 100 & Excellent & 2.3 & 0.80 & 73 & Good \\
3.66 & 0.11 & 86.6 & Excellent & 2.1 & 0.60 & 71 & Good \\
3.22 & 0.72 & 82.2 & Very Good & 1.9 & 0.40 & 69 & Good \\
2.98 & 0.48 & 79.8 & Very Good & 1.5 & 0.00 & 65 & Good \\
2.7 & 0.20 & 77 & Very Good & & & & \\
\hline
\end{tabular}




\subsection{Faculty of science}

The second dataset is collected from faculty of science. The range of GPA points are less than the range in dataset 1 . Table 3 , shows three columns that represents the GPA in points, the awarded degree and the percentage.

Table 5 also shows the calculated minimum points (Min Points), maximum points (Max Points), minimum percentage (Min_Per) and maximum percentage (Max_Per) to cumulative GPA for dataset 3. As shown in Table 6 and Figure 3, the novel equations are tested by calculating the percentage of a given cumulative GPA of some students in the given dataset shown in Table 5.

From the previous evaluations and results, we can conclude that; fuzzy set theory has the potential to produce models that are more comprehensible, less complex, and more robust; fuzzy information granulation appears to be an ideal tool for trading off accuracy against complexity and understand ability.

- Fuzzy set theory can generate more comprehensible, less complicated and more stable models; fuzzy granulation of information is apparently an excellent method to trad off accuracy versus complexity and ability understanding.

- Data mining appears to be extremely helpful in fuzzy approaches to represent ambiguous patterns, which is crucial in many application areas.

- In accordance with the principle of probability, fixation index (FST) will make a major contribution to modeling and analyzing diverse sources of knowledge that are unknown and incomplete.

- $\quad$ For data pre-processing and post processing, fuzzy approaches seem to be especially useful.

Table 5. Dataset 3-faculty of clinical pharmacy

\begin{tabular}{cccclll}
\hline Max Per & Min Per & Max Points & Min Points & \multicolumn{1}{c}{ Percentage } & Awarded Degree & Points \\
\hline 100 & 90 & 5 & 4 & Percentage $>=90$ & Excellent & GPA $>=4$ \\
$<90$ & 85 & $<4$ & 3.7 & $90>$ Percentage $>=85$ & Excellent & $4>$ GPA $>=3.7$ \\
$<85$ & 82.5 & $<3.7$ & 3.3 & $85>$ Percentage $>=82.5$ & Very Good & $3.7>$ GPA $>=3.3$ \\
$<82.5$ & 77.5 & $<3.3$ & 3 & $82.5>$ Percentage $>=77.5$ & Very Good & $3.3>$ GPA $>=3$ \\
$<77.5$ & 75 & $<3$ & 2.7 & $77.5>$ Percentage $>=75$ & Very Good & $3>$ GPA $>=2.7$ \\
$<75$ & 72.5 & $<2.7$ & 2.3 & $75>$ Percentage $>=72.5$ & Good & $2.7>$ GPA $>=2.3$ \\
$<72.5$ & 67.5 & $<2.3$ & 2 & $72.5>$ Percentage $>=67.5$ & Good & $2.3>$ GPA $>=2$ \\
$<67.5$ & 65 & $<2$ & 1.7 & $67.5>$ Percentage $>=65$ & Good & $2>$ GPA $>=1.7$ \\
$<65$ & 62.5 & $<1.7$ & 1.3 & $65>$ Percentage $>=62.5$ & Pass & $1.7>$ GPA $>=1.3$ \\
$<62.5$ & 60 & $<1.3$ & 1 & $62.5>$ Percentage $>=60$ & Pass & $1.3>$ GPA $>=1$ \\
$<60$ & 0 & $<1$ & 0 & $60>$ Percentage & Fail & $1>$ GPA \\
\hline
\end{tabular}

Table 6. Percentage calculations for a given cumulative GPA for dataset 3

\begin{tabular}{ccrl}
\hline Cumulative GPA & Member & Percentage & Awarded Degree \\
\hline 4.2 & 0.20 & 92.00 & Excellent \\
4 & 0.00 & 90.0 & Excellent \\
3.5 & 0.50 & 83.75 & Very Good \\
2.8 & 0.33 & 75.83 & Very Good \\
2.1 & 0.33 & 69.17 & Good \\
1.8 & 0.33 & 65.83 & Good \\
1.5 & 0.50 & 63.75 & Pass \\
1.1 & 0.33 & 60.83 & Pass \\
\hline
\end{tabular}

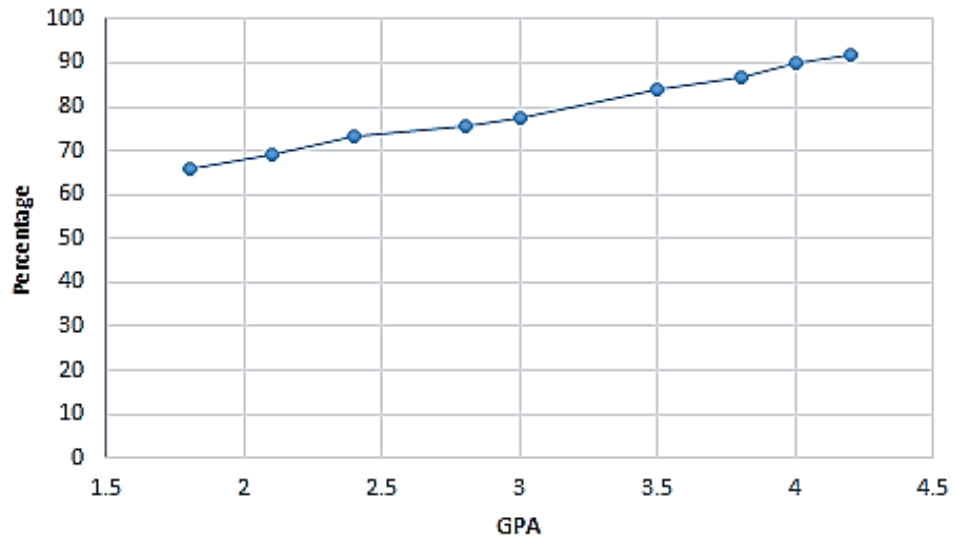

Figure 3. Relation between cumulative GPA and percentage for dataset 3 


\section{CONCLUSION}

In this study, we presented a novel model that transforms between the awarded cumulative GPA and the awarded percentage ranking based on fuzzy system. The proposed solution will help students that need to transfer between universities that used different awarded criteria and help in comparing between graduates students if they awarded in different criteria. We have decided to investigate these mechanisms under the fuzzy paradigm as it is considered one of the hypotheses that best describe those elements of human comprehension and reasoning. Results in three different data sets show that the proposed model can convert the awarded cumulative GPA to an awarded percentage.

\section{REFERENCES}

[1] X. D. Keating et al., "Tracking changes of Chinese pre-service teachers' aerobic fitness, body mass index, and grade point average over 4-years of college," International journal of environmental research and public health, vol. 16, p. 966, 2019, doi: 10.3390/ijerph16060966.

[2] R. D. Richardson, and R. L. Williams, "Linkages Between Grade Point Average and Student Ratings," Journal of Educational Research and Practice, vol. 11, p. 2, 2021, doi: 10.5590/JERAP.2020.11.1.02.

[3] M. N. Aung, V. Jaroonvanichkul, J. Deerojanawong, J. Somboonwong, I. Ahmad, and P. Wannakrairot, "A New Method for Setting Standard in Medical Education, Applying Previous Year Cumulative GPA," European Journal of Medical and Health Sciences, vol. 1, 2019, doi: 10.24018/ejmed.2019.1.5.114.

[4] S. El Sheikh, Y. Tawfik Halim, H. Ibrahim Hamdy, and M. Samy El-deeb, "The Impact of Enhancing the Academic Performance on Student Satisfaction of Private Business Faculties: New Business Model for Egyptian Private Universities," Journal of alexandria University for Administrative Sciences, vol. 57, pp. 1-34, 2020, doi: 10.21608/acj.2020.121759.

[5] O. Analytica, "Egypt education will decline under demographic growth," Emerald Expert Briefings, 2019.

[6] A. Mutaliba, S. Razalib, and M. Aqszac, "Assessment of Student Achievement using the Cumulative Grade Point Average (CGPA) and the Integrated Cumulative Grade Point Average (ICGPA)," International Journal of Innovation, Creativity and Change, vol. 9, no. 6, 2019.

[7] J. Hansen, P. Sadler, and G. Sonnert, "Estimating high school GPA weighting parameters with a graded response model," Educational Measurement: Issues and Practice, vol. 38, pp. 16-24, 2019, doi: 10.1111/emip.12203.

[8] P. A. Westrick, "Reliability estimates for undergraduate grade point average," Educational Assessment, vol. 22, pp. 231-252, 2017, doi: 10.1080/10627197.2017.1381554.

[9] P. K. Srivastava and D. C. Bisht, "Recent trends and applications of fuzzy logic," In Advanced Fuzzy Logic Approaches in Engineering Science, 2019, pp. 327-340, doi: 10.4018/978-1-5225-5709-8.ch015.

[10] U. Ghani, I. S. Bajwa, and A. Ashfaq, "A fuzzy logic based intelligent system for measuring customer loyalty and decision making," Symmetry, vol. 10, p. 761, 2018, doi: 10.3390/sym10120761.

[11] R. Bělohlávek, J. W. Dauben, and G. J. Klir, "Fuzzy logic and mathematics: a historical perspective" Oxford University Press, 2017, doi: 10.1093/oso/9780190200015.001.0001.

[12] P. D. Asanka and A. S. Perera, "Defining fuzzy membership function using box plot," International journal of research in computer applications and robotics, vol. 5, pp. 1-10, 2017.

[13] L. W. Hawkes, S. J. Derry, and E. A. Rundensteiner, "Individualized tutoring using an intelligent fuzzy temporal relational database," International Journal of Man-Machine Studies, vol. 33, pp. 409-429, 1990, doi: 10.1016/S0020-7373(05)80040-9.

[14] L. W. Hawkes and S. J. Derry, "Advances in local student modeling using informal fuzzy reasoning," International journal of human-computer studies, vol. 45, pp. 697-722, 1996, doi: 10.1006/ijhc.1996.0075.

[15] L. B. Nilson, "Specifications grading: Restoring rigor, motivating students, and saving faculty time," Stylus Publishing, LLC, 2015.

[16] H.-J. Rong, P. P. Angelov, X. Gu, and J.-M. Bai, "Stability of evolving fuzzy systems based on data clouds," IEEE Transactions on Fuzzy Systems, vol. 26, pp. 2774-2784, 2018, doi: 10.1109/TFUZZ.2018.2793258.

[17] K. Warendorf and S. J. Tsao, "Application of fuzzy logic techniques in the BSS1 tutoring system," Journal of Artificial Intelligence in Education, vol. 8, pp. 113-146, 1997.

[18] C. Herzog, "Fuzzy techniques for understanding student solutions in intelligent tutoring systems, Papers for the Seventh Meeting of GI Section 1.1. 5/7.0. 1, Intelligent Tutoring Systems," Research Institute for ApplicationOriented Knowledge Processing (FAW), Germany, 1994.

[19] J. Holt and A. W. Leach, "Linguistic variables as fuzzy sets to model uncertainty in the combined efficacy of multiple phytosanitary measures in pest risk analysis," Ecological Modelling, vol. 406, pp. 73-79, 2019, doi: 10.1016/j.ecolmodel.2019.04.017.

[20] C. Troussas and C. Sgouropoulou, "Innovative Trends in Personalized Software Engineering and Information Systems: The Case of Intelligent and Adaptive E-learning Systems" IOS Press, 2020, vol. 324.

[21] M. Cantabella, R. Martínez-España, B. Ayuso, J. A. Yáñez, and A. Muñoz, "Analysis of student behavior in learning management systems through a Big Data framework," Future Generation Computer Systems, vol. 90, pp. 262-272, 2019, doi: 10.1016/j.future.2018.08.003.

[22] M. Samarakou, P. Prentakis, D. Mitsoudis, D. Karolidis, and S. Athinaios, "Application of fuzzy logic for the assessment of engineering students," In 2017 IEEE Global Engineering Education Conference (EDUCON), 2017, pp. 646-650, doi: 10.1109/EDUCON.2017.7942914. 
[23] M. Al Duhayyim and P. Newbury, "Concept-based and Fuzzy Adaptive E-learning," In Proceedings of the 2018 The 3rd International Conference on Information and Education Innovations, 2018, pp. 49-56, doi: $10.1145 / 3234825.3234832$.

[24] P.-C. Sue, J.-F. Weng, J.-M. Su, and S.-S. Tseng, “A new approach for constructing the concept map," In IEEE International Conference on Advanced Learning Technologies, 2004. Proceedings., 2004, pp. 76-80, doi: 10.1109/ICALT.2004.1357378.

[25] A. Canales, A. Peña, R. Peredo, H. Sossa, and A. Gutiérrez, "Adaptive and intelligent web based education system: Towards an integral architecture and framework," Expert systems with applications, vol. 33, pp. 1076-1089, 2007, doi: 10.1016/j.eswa.2006.08.034.

[26] I. Lykourentzou, I. Giannoukos, V. Nikolopoulos, G. Mpardis, and V. Loumos, "Dropout prediction in e-learning courses through the combination of machine learning techniques," Computers \& Education, vol. 53, pp. 950-965, 2009, doi: 10.1016/j.compedu.2009.05.010.

[27] A. Varghese, J. P. Sreedhar, S. Kolamban, and S. Nayaki, "Outcome based assessment using fuzzy logic," International Journal of Advanced Computer Science and Applications, vol. 8, no. 1, 2017, doi: 10.14569/IJACSA.2017.080115.

[28] C. Troussas, K. Chrysafiadi, and M. Virvou, "An intelligent adaptive fuzzy-based inference system for computerassisted language learning," Expert Systems with Applications, vol. 127, pp. 85-96, 2019, doi: 10.1016/j.eswa.2019.03.003.

[29] N. Amelia, A. G. Abdullah, and Y. Mulyadi, "Meta-analysis of student performance assessment using fuzzy logic," Indonesian Journal of Science and Technology, vol. 4, no. 1, pp. 74-88, 2019, doi: 10.17509/ijost.v4i1.15804.

[30] G.Vasanti, "Grade Card Model using Fuzzy Logic," International Journal of Innovative Technology and Exploring Engineering (IJITEE), vol. 8, 2019, doi: 10.35940/ijitee.F1148.0486S419.

\section{BIOGRAPHIES OF AUTHORS}
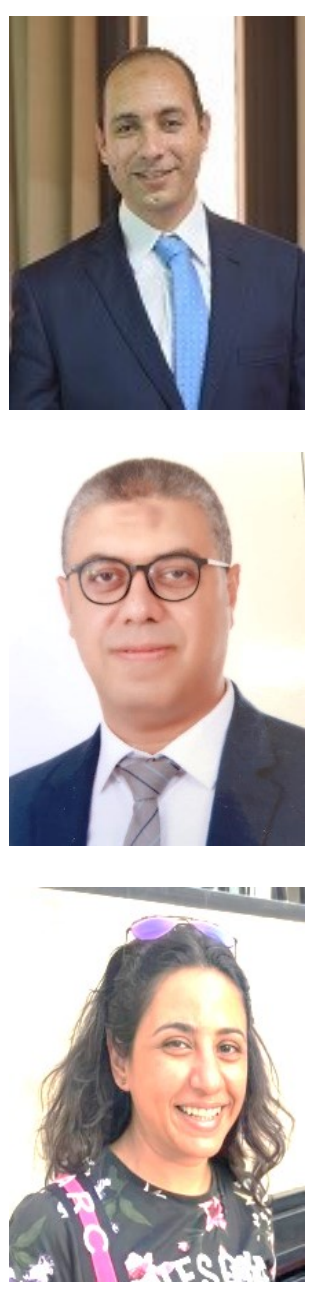

Farid Ali Mousa is an associate prof. in information technology department, faculty of computers and artificial intelligence, Beni-Suef University. He received his $\mathrm{PhD}$ degree in information technology from Cairo University. Research interest points include soft computing, data minig, machine learning, and natural language processing.

Email: fared.ali@fcis.bsu.edu.eg and faly@msa.edu.eg.

Ibrahim Eldesoky Fattoh is an associate prof. in computer science department, faculty of computers and artificial intelligence, Beni-Suef University. He received his $\mathrm{PhD}$ degree in computer science from Helwan University. Research interest points include soft computing, data minig, machine learning, and natural language processing.

Email: Ibrahim_desoky@fcis.bsu.edu.eg and ibrahim.abdelmageed@fue.edu.eg.

Soha Safwat Labib is an associate prof. and head of software engineering and information technology depertment, faculty of engineering and technology, the Egyptian Chinese University. She received his $\mathrm{PhD}$ degree in computer scoience from Cairo University. Research interest points include soft computing, data minig, machine learning, and natural language processing.

Email: ssafwat@ecu.edu.eg 